\title{
A Study on Factors for Conversion from Laparoscopic Cholecystectomy to open Cholecystectomy
}

\author{
${ }^{1}$ Dr.S. Babu M.S , ${ }^{2}$ Dr.J,Ravi Sankar. M.S \\ (Associate Professor, Vellammal Medical College, \&hospital.Madurai.) \\ (Associate professor, Department of General Surgery, Thoothukudi medical college and hospital, INDIA)
}

\begin{abstract}
Aim:
1. To study the factors that lead to conversion from Laparoscopic cholecystectomy to open method in regard to age, sex, clinical presentation, laboratory values, Ultrasonogram and Operative findings.

2. To assess preoperative factors that might predict the chances of conversion

3. To assess the intra operative reason that results to conversion.

Materials and methods: This study was conducted in the Department of General surgery and Department of Surgical Gastroenterology in Madurai Medical College and Government Rajaji Hospital, Madurai from October 2010 to September 2012 for a period of two years. This is a retrospective study done in the Madurai Medical College and Government Rajaji Hospital. The details of all the patients who underwent and attempted Laparoscopic cholecystectomy in the Department of General surgery and Department of Surgical Gastroenterology in Madurai Medical College and Government Rajaji Hospital, Madurai were collected from the Medical Records Department
\end{abstract}

Keywords: Cholecystectomy, Laproscopic Cholecystectomy, Open Cholecystectomy

\section{Results}

Two hundred and seventy six patients were posted for laparoscopic cholecystectomy for cholelithiasis without choledocholithiasis were selected. 24 patients of 276 cases who underwent laparoscopic cholecystectomy of posted cases had to be converted to open cholecystectomy for various reasons. They are depicted in Table 1.Fig.1.

Table 1: Various reasons for conversion of laparascopic cholecystectomy to open method cholecystectomy.

\begin{tabular}{|l|l|l|l|}
\hline $\begin{array}{l}\text { S. } \\
\text { No }\end{array}$ & $\begin{array}{l}\text { Reason for conversion to open } \\
\text { cholecystectomy }\end{array}$ & $\begin{array}{l}\text { No of } \\
\text { cases }\end{array}$ & Percentage \\
\hline 1 & Dense adhesions and difficult anatomy & 13 & 54.16 \\
\hline 2 & Post operative adhesions & 2 & 8.33 \\
\hline 3 & Bleeding from the cystic artery & 2 & 8.33 \\
\hline 4 & Spillage of stones & 2 & 8.33 \\
\hline 5 & Common bile duct injury & 1 & 4.16 \\
\hline 6 & Suspected injury to intestine & 1 & 4.16 \\
\hline 7 & Instrument failure & 1 & 4.16 \\
\hline 8 & Pneumoperitoneum related complication & 1 & 4.16 \\
\hline 9 & Wide cystic duct & 1 & 4.16 \\
\hline
\end{tabular}

Fig.1. Various reasons for conversion of laparascopic cholecystectomy to open method cholecystectomy.

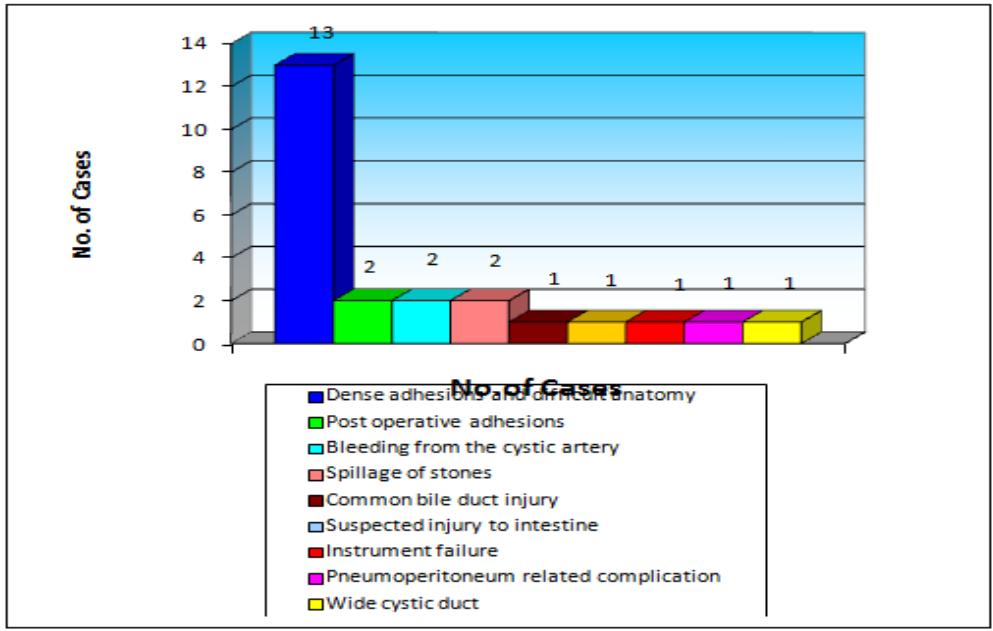


The most common reason for conversion found in our study in the 24 cases that were converted to open cholecystectomy was dense adhesions between omentum and visceral organs to the gallbladder fossa in 13 patients leading to inability to define the anatomy clearly precluded to conversion in these cases. It is followed by previous history of laparatomy with post operative adhesions leading difficulty in trocar placement and access to the peritoneal cavity. Also the vascular complications like bleeding from the cystic artery, other intraoperative complications like spillage of stones, common bile duct injury, inability to manage cystic duct laparoscopically and other complications like instrument failure and anesthesia related complication have also precluded to conversion.

\section{Discussion}

In our study, we found 24 cases of laparoscopic cholecystectomy converted to open cholecystectomy out of 276 cases. Incidence of conversion to open method is higher among male patients that are 8 out of 34 cases with a ratio of 1:3 when compared to the female patients with conversion ratio at 1:15 like published in studies like Kanaan et al. It could have been due to the large number of difficult cholecystectomy observed in male patients while many studies in the high volume centres performing high number of laparoscopic cholecystectomy shown results at a rate of 1:7 to 1:20 cases. The results also can be explained due to the presentation after multiple episodes of cholecystitis in our study. This also partly explains the conversion observed in all the cases which was found to be at a rate of 1:11. We had three diabetic patients in whom laparoscopic method was converted to open method. Diabetic patients are more prone for complications due to their altered immune status and prediction for conversion should be more if a diabetic patient with uncontrolled diabetic status and with features of acute cholecystitis, impacted gall stone.We had about 13 patients with dense adhesions to omentum and visceral organs to the gallbladder fossa which was found out to be primary reason behind in most of the conversions in our study. The difficulty in releasing adhesions is primarily due to inability to define anatomy lead to the conversion to open cholecystectomy and sometimes due to the injury of blood vessels or injury to the bowel. The methods that can be done with dense adhesions to prevent the conversion can be approached laparoscopically by Laparoscopic subtotal cholecystectomy with fundus first method or Cholecystostomy in certain scenarios allows to exit from difficult situation, allowing the inflammation to subside and opportunity to do cholecystectomy in 6 to 8 weeks.

Factors associated with dense adhesions and thereby increasing the conversion rate are primarily cholecystitis particularly in the acute stage, older age group, Male gender and the co morbid conditions particularly diabetes mellitus and the timing of surgery after 72 hours, allowing adhesions difficult for the dissection laparoscopically as observed in the similar study by Cox MR et al. Koo et al observed conversion rate of $12 \%$ and $30 \%$ in patients operated within and after 72 hours in cases of acute cholecystitis. It describes the importance of decision making in deciding the timing of the surgery. Previous abdominal surgery postoperative adhesions lead to conversion in two cases. In both cases there were dense adhesions to parietal wall and gallbladder fossa. Adhesiolysis through laparoscopy was tried but access to release adhesions was limited and fear of injury to bowel and CBD and other neighboring structures. We had 72 patients with adhesions either from previous inflammation or in some cases previous surgery. Adhesiolysis was done laparoscopically by blunt and sharp dissection with use of cautery when needed. After adhesiolysis cholecystectomy was done in a routine manner. Owing to difficulty additional $5 \mathrm{~mm}$ port was created for instrumentation and manipulation in some cases. Pneumo peritoneum could be carried out by open method like Fried G.M.et al. who used open insertion of initial port, and at times gained initial access through upper quadrant.

Spillage of stone in one patient and fear of spillage in other patient was the cause of conversion as shown by results from Frazee R.C. et al. In other cases with multiple calculi where we suspected spillage, gall bladder was retrieved with self designed retrieval bag which can be used in preventing spillage and subsequently the complications of it. If spillage was minimal as in many cases with tiny calculi and sludge, were managed with irrigation and suction. The source of bleeding during laparoscopic cholecystectomy may be from the trocar site or during the adhesiolysis can result in bleeding from omentum which can be controlled by careful elecro cautery or commonly due to the sudden pulsatile bleeding can occur from cystic artery unexpectectly and in some cases due to the anomalous vessels.In our study, we had two cases of conversion due to the bleeding from the cystic artery. These vascular complications can be prevented by meticulous dissection and careful dissection by avoiding clipping blindly in panic and it can be approached by placing additional trocar can be placed for visualization and manipulation and gallbladder can be pushed against Calot's triangle providing temporary hemostasis and Irrigation and suction can show the exact site of bleeding to control using electro cautery. If these measures fail and bleeding is significant, laparatomy should be done. Also the roles of operating and assisting surgeon are important in identifying the bleeding vessels and also suspicions of anomalous vessels need to be remembered. Bleeding from gall bladder fossa can be a cause for conversion in cases like cirrhosis liver. In our study, we had no significant bleeding from the gall bladder fossa to the extent that needs conversion 
and all cases with minor oozing were treated with compression, Unlike in the studies by Perissa et al and Sanabria et al who observed significant cases of conversion due to it particularly in the cirrhotic patients. We had one patient with bile duct injury. It was recognized intraoperatively suspecting bile leak and on further dissection exposed the trasected common bile duct which was mistaken for cystic duct was clipped and cut. Laparatomy was done through a midline incision and the injury was assessed and with experienced surgeon, hepatico jejunostomy was done.

'It can be prevented by cephalad retraction of gall bladder which helps in making the cystic duct lie in line with common bile duct making it prone to injury which can be prevented lateral and superior retraction of infundibulum of gall bladder and also by avoiding the excessive retraction of gall bladder when clips were applied may injure common bile duct and also by avoiding excessive use of cautery near the triangle of Calot. Inability to define anatomy with restricted instrumentation lead to the decision of conversion. Instrument/Equipment failure a cause of conversion as observed in studies by Gopmnyhet al. and Kumar et al.

\section{Conclusion}

An appreciation of these factors would predict the conversion that will allow appropriate planning by the patient, the institution, and the surgeon. Of the 276 patients in whom laparoscopic cholecystectomy was attempted, 26(9.4\%) required conversion to open surgery. The most common reason for conversion was inability to define anatomy in patients with inflamed gallbladder $(n=13)$. Significant predictive factors for conversion were male gender, previous abdominal surgery, associated dibetes, acute cholecystitis and thickened gallbladder wall with pericholecytitic collection on preoperative ultrasonography. These factors are of more of importance when these factors are associated with each other than its independent presence in predicting difficult cholecystectomy.

\section{Bibiliography}

[1]. Mouret P. From the first laparoscopic cholecystectomy to the frontier of laparoscopic surgery: The future perspective. DigSurg1991; 8: 124-5.

[2]. NIH Consensus Conference. Gallstones and Laparoscopic Cholecystectomy.JAMA 1993; 269: 1018-24

[3]. Lo CM, Fan ST, Liu CL et al. Early decision for conversionof laparoscopic to open cholecystectomy for treatment of acute cholecystitis. AmJrSurg1997; 173: 513-17.

[4]. Kama NA, Kologlu M, Doganay M et al. A risk score forconversion from laparoscopic to open cholecystectomy. AmJrSurg2001; 181: 520-25.

[5]. Yu SC, Chen SC, Wang SM et al. Is previous abdominalsurgery a contraindication to laparoscopic cholecystectomy? JrLaparoendoscSurg1994; 4: 31-5.

[6]. Fried GM, Barkun JS, Sigman $\mathrm{HH}$ et al. Factors determining conversion to laparatomy in patients undergoing laparoscopicCholecystectomy. AmJrSurg1994; 167: 35-41.

[7]. Alponat A, Kum CK, Koh BC et al. Predictive factors for conversion of laparoscopic cholecystectomy. World JrSurg1997; 21:62933.

[8]. Liu CL, Fan ST, Lai EC et al. Factors affecting conversion of laparoscopic cholecystectomy to open surgery. Arch Surg1996: 131: 98-101.

[9]. Hershmann MJ and Rosin RD. Laparoscopic laser cholecystectomy: our first 200 patients. Ann R CollSurg Engl1992; 74:242-47.

[10]. Mahmud S, Masaud M, Canna K et al. Fundus - first laparoscopic

[11]. Cholecystectomy. SurgEndosc2002: 16: 581-84.

[12]. Lo CM, Liu CL, Fan ST, et al: Prospective randomized study of early versus delayed laparoscopic cholecystectomy for acute cholecystitis. Ann Surg 1998; 227:461-467.

[13]. Lai PB, Kwong KH, Leung KL, et al: Randomized trial of early versus delayed laparoscopic cholecystectomy for acute cholecystitis. Br J Surg 1998; 85:764-767.

[14]. Kiviluoto T, Siren J, Luukkonen P, et al: Randomised trial of laparoscopic versus open cholecystectomy for acute and gangrenous cholecystitis. Lancet 1998; 351:321-325.

[15]. Steiner CA, Bass EB, Talamini MA, et al: Surgical rates and operative mortality for open and laparoscopic cholecystectomy in Maryland. N Engl J Med 1994; 330:403-408.

[16]. Southern Surgeons Club: A prospective analysis of 1518 laparoscopic cholecystectomies. N Engl J Med 1991; 324:1073-1078.

[17]. Lau H, Lo CY, Patil NG, et al: Early versus delayed-interval laparoscopic cholecystectomy for acute cholecystitis: A meta analysis. Surg Endosc 2006; 20:82-87.

[18]. Willsher PC, Sanabria JR, Gallinger S, et al: Early laparoscopic cholecystectomy for acute cholecystitis: A safe procedure. J GastrointestSurg 1999; 3:50-53.

[19]. Liu TH, Consorti ET, Kawashima A, et al: Patient evaluation and management with selective use of magnetic resonance cholangiography and endoscopic retrograde cholangio pancreatography before laparoscopic cholecystectomy. Ann Surg 2001; 234:33-40.

[20]. Rhodes M, Sussman L, Cohen L, et al: Randomized trial of laparoscopic exploration of common bile duct versus postoperative endoscopic retrograde cholangiography for common bile duct stones. Lancet 1998; 351:159-161.

[21]. Boerma D, Rauws EA, Keulemans YC, et al: Wait-and-see policy or laparoscopic cholecystectomy after endoscopic sphincterotomy for bile-duct stones: A randomized trial. Lancet 2002; 360:761-765.

[22]. Linder JD, Klapow JC, Linder SD, et al: Incomplete response to endoscopic sphincterotomy in patients with sphincter of Oddi dysfunction: Evidence for a chronic pain disorder. Am J Gastroenterol 2003; 98:1738-1743.

[23]. Lau H, Brooks DC: Transitions in laparoscopic cholecystectomy: The impact of ambulatory surgery. Surg Endosc 2002; 16:323326. 
[24]. Calland JF, Tanaka K, Foley E, et al: Outpatient laparoscopic cholecystectomy: Patient outcomes after implementation of a clinical pathway. Ann Surg 2001; 233:704-715.

[25]. Flum DR, Dellinger EP, Cheadle A, et al: Intraoperative cholangiography and risk of common bile duct injury during cholecystectomy. JAMA 2003; 289:1639-1644.

[26]. Halpin VJ, Dunnegan D, Soper NJ: Laparoscopic intra corporeal ultrasound versus fluorescent.

[27]. Conversion in Laparoscopic Cholecystectomy: An Evaluation Study Ajay Anand, B.S. Pathania, Gurjeet Singh

[28]. Blumgart: Surgery of the Liver, Biliary Tract and Pancreas, 5th ed. 